\title{
Characteristics of CARMA1-BCL10-MALT1-A20-NF-KB expression in T cell-acute lymphocytic leukemia
}

Yu Ma ${ }^{1 \dagger}$, Ziwei Liao ${ }^{1 \dagger}$, Yi X $^{1 \dagger}$, Ziyun Zhong ${ }^{2}$, Xu Wang ${ }^{1,3}$, Fan Zhang ${ }^{1}$, Shaohua Chen ${ }^{1}$, Lijian Yang ${ }^{1}$, Gengxin Luo ${ }^{1}$, Xin Huang ${ }^{4}$, Suming Huang ${ }^{5}$, Xiuli $\mathrm{Wu}^{1^{*}}$ and Yangqiu $\mathrm{Li}^{1,3^{*}}$

\begin{abstract}
Background: Knowledge of the oncogenic signaling pathways of T-cell acute lymphoblastic leukemia (T-ALL) remains limited. Constitutive aberrant activation of the nuclear factor kappa B (NF-kB) signaling pathway has been detected in various lymphoid malignancies and plays a key role in the development of these carcinomas. The zinc finger-containing protein, A20, is a central regulator of multiple NF-kB-activating signaling cascades. A20 is frequently inactivated by deletions and/or mutations in several B-and T-cell lymphoma subtypes. However, few A20 mutations and polymorphisms have been reported in T-ALL. Thus, it is of interest to analyze the expression characteristics of $A 20$ and its regulating factors, including upstream regulators and the CBM complex, which includes CARMA1, BCL10, and MALT1.
\end{abstract}

Methods: The expression levels of CARMA1, BCL10, MALT1, A20, and NF-KB were detected in peripheral blood mononuclear cells (PBMCs) from 21 patients with newly diagnosed T-ALL using real-time PCR, and correlations between the aberrant expression of these genes in T-ALL was analyzed. Sixteen healthy individuals, including 10 males and 6 females, served as controls.

Results: Significantly lower A20 expression was found in T-ALL patients (median: 4.853) compared with healthy individuals (median: 8.748; $P=0.017$ ), and significantly increased expression levels of CARMA1 (median: 2.916; $P=0.034$ ), BCL10 (median: 0.285; $P=0.033$ ), and MALT1 (median: 1.201; $P=0.010$ ) were found in T-ALL compared with the healthy individuals (median: $1.379,0.169$, and 0.677 , respectively). In contrast, overexpression of NF-KB (median: 0.714 ) was found in T-ALL compared with healthy individuals (median: $0.335 ; P=0.001$ ). A negative correlation between the MALT1 and A20 expression levels and a positive correlation between CARMA1 and BCL10 were found in T-ALL and healthy individuals. However, no negative correlation was found between $A 20$ and NF-KB and the MALT1 and NF-KB expression level in the T-ALL group.

Conclusions: We characterized the expression of the CARMA-BCL10-MALT1-A20-NF-KB pathway genes in T-ALL. Overexpression of CARMA-BCL10-MALT in T-ALL may contribute to the constitutive cleavage and inactivation of A20, which enhances NF-KB signaling and may be related to T-ALL pathogenesis.

Keywords: A20, CARMAT-BCL10-MALT1, T-cell acute lymphoblastic leukemia

\footnotetext{
*Correspondence: siulier@163.com; yangqiuli@hotmail.com

${ }^{\dagger}$ Equal contributors

'Institute of Hematology, Jinan University, Guangzhou 510632, China

${ }^{3}$ Key Laboratory for Regenerative Medicine of Ministry of Education, Jinan

University, Guangzhou 510632, China

Full list of author information is available at the end of the article
} 


\section{Background}

T-cell acute lymphoblastic leukemia (T-ALL), which accounts for $15 \%$ of all newly diagnosed ALL cases in children and 20 to $25 \%$ of ALL cases in adults, results from clonal malignant T-cell proliferation, is an aggressive malignancy that does not respond well to chemotherapy, and has poorer prognosis than its B-cell counterpart [1-3]. The cellular biology and pathogenesis of T-ALL are relatively complex, and these might be related to the different original malignant T-cell clone, e.g., T-ALL cases with two malignant $\mathrm{T}$-cell clones or a mono-malignant T-cell clone have different gene expression patterns [4-6]. It has also been reported that the acute and lymphoma subtypes of adult T-cell leukemia/lymphomas are genomically distinct; thus, they may develop tumors via different genetic pathways as suggested by comparative analysis of their genomic profiles [7]. Complex acquired genetic aberrations include chromosomal translocations, and gene rearrangements and mutations, resulting in the abnormal expression of oncogenes such as Notch1, TAL1 (T-cell acute lymphoblastic leukemia 1), and $B C L 11 B$ (B-cell chronic lymphocytic leukemia/lymphoma 11B), which may be associated with advanced disease and resistance to treatment [8-14]. In contrast, abnormal T-cell activation is vital for cellular transformation, and various signaling pathways are triggered by the T-cell receptor that play key roles in controlling T-cell activation. For example, recent findings define MALT1 (mucosa-associated-lymphoid-tissue lymphoma-translocation gene 1) as a protein with proteolytic activity that controls T-cell activation by regulating key molecules in T-cell receptor (TCR)-induced signaling pathways [15]. Moreover, a number of studies have shown that in A20 (tumor necrosis factor- $\alpha$-induced protein 3; TNFAIP3), which is a nuclear factor kappa B (NF- $\mathrm{kB}$ ) negative regulator, genetic alterations are frequently found in lymphomas, suggesting that there may be a link between the altered immune response and leukemogenesis [16-23]. Furthermore, it was shown that TCR stimulation induces the recruitment of A20 into a CBM complex containing CARMA1 (caspase-recruitment domain (CARD) containing membrane-associated guanylate kinase protein 1 , also called CARD11), adaptor protein Bcl-10 (B-cell lymphoma 10), and MALT1 (paracaspase mucosa-associated lymphoid tissue lymphoma translocation gene 1), leading to MALT1-mediated A20 processing. MALT1 cleaves human A20 after arginine 439 and impairs its NF- $k B$-inhibitory function. A20 is a substrate of MALT1, underscoring the importance of MALT1 proteolytic activity in the 'fine tuning' of TCR signaling [24].

A20 is frequently inactivated by deletions and/or mutations in several lymphoma subtypes including B- and T-cells [16-22]. Recently, bi- and monoallelic A20 deletions in a high proportion of Sezary syndrome patients and a biallelic $A 20$ deletion in the Sezary syndromederived cell line SeAx were identified. Furthermore, A20 inhibition activates the NF- $\mathrm{kB}$ pathway, thereby increasing the proliferation of normal T-cells [17]. Interestingly, we recently found that there are rare $A 20$ mutations and polymorphisms in T-ALL [25]. Therefore, it is of interest to analyze the expression characteristics of $A 20$ and its regulating factors, including upstream components of the CBM complex, which includes CARMA1, BCL10, and MALT1 [24,26-28], which is expected to provide new insight in the abnormal molecular regulation on $\mathrm{T}$ cell activation. In this study, we characterized the gene expression pattern of $A 20$, as well as the gene expression levels of its upregulating factors CARMA1-BCL10MALT1 and its target factor NF-kB in T-ALL.

\section{Methods}

\section{Samples}

The samples used in this study were derived from 21 newly diagnosed, untreated patients with T-ALL, including 17 males and 4 females ( 4 to 66 years old; median age: 23.5 years). Sixteen healthy individuals including 10 males and 6 females (17 to 45 years old; median age: 26 years) served as controls. Peripheral blood mononuclear cells (PBMCs) were isolated from heparinized venous blood by Ficoll-Paque gradient centrifugation. RNA extraction and cDNA synthesis from PBMCs were performed according to the manufacturer's instructions. All human peripheral blood samples were obtained with consent from the human subjects. All procedures were conducted according to the guidelines of the Medical Ethics Committee of the Health Bureau of Guangdong Province in China, and ethical approval was obtained from the Ethics Committee of the Medical School of Jinan University.

\section{Quantitative real-time RT-PCR (qRT-PCR)}

The sequences of the primers used for CARMA1, BCL-10, $M A L T 1, A 20$, and $N F-\kappa B$ gene amplification are listed in Table 1. The expression level of the CARMA1, BCL-10, $M A L T 1, A 20, N F-\kappa B$, and $\beta 2$-microglobulin $(\beta 2 M)$ genes was determined by SYBR Green I real-time PCR as previously described $[4,25,29,30]$. The relative amounts of the genes of interest and the $\beta 2 M$ reference gene were measured in two independent assays. The specific, amplified PCR products were analyzed by melting curve analysis. The data are presented as the relative expression of the genes of interest compared with the internal control gene as determined by the $2\left(^{-\triangle \mathrm{CT}}\right)$ method $[4,28-30]$.

\section{Statistical analysis}

Two independent-samples Mann-Whitney $U$ tests were performed to compare the median expression level of each gene between patients with T-ALL and control 
Table 1 List of primers used for real-time RT-PCR

\begin{tabular}{ll}
\hline Primer & Sequence \\
\hline CARMA1-f & $5^{\prime}$-ttgtgggagaatgtggagtgt-3' \\
CARMA1-r & $5^{\prime}$-tgccccttggtatgtagaatg-3' \\
BCL10-f & $5^{\prime}$-cccgctccgcctcctctcctt-3' \\
BCL10-r & $5^{\prime}$-ggcgcttcttccgggtccg-3' \\
MALT1-f & $5^{\prime}$-tcttggctggacagtttgtga-3' \\
MALT1-r & $5^{\prime}$-gctctctgggatgtcgcaa-3' \\
A20-f & $5^{\prime}$-ctgggaccatggcacaactc-3' \\
A20-r & $5^{\prime}$-cggaaggttccatgggattc-3' \\
NF-KB-f & $5^{\prime}$-ccacaagacagaagctgaag-3' \\
NF-KB-r & $5^{\prime}$-agatactatctgtaagtgaacc-3' \\
$\beta_{2}$ M-f & $5^{\prime}$-tacactgaattcacccccac-3' \\
$\beta_{2}$ M-r & $5^{\prime}$-catccaatccaaatgcggca-3' \\
\hline
\end{tabular}

individuals. Spearman correlation and linear regression analyses were used to determine the association between different genes in different groups. A $P<0.05$ was considered statistically significant $[29,30]$.

\section{Results and discussion}

Despite significant improvement in our understanding of T-ALL biology and pathogenesis, knowledge of the oncogenic signaling pathways involved in T-ALL remains limited. Constitutive aberrant activation of the NF- $\mathrm{kB}$ signaling pathway has been detected in various lymphoid malignancies, and it plays a key role in the development of these tumors. A20 is a central regulator involved in the negative feedback regulation of multiple NF- $\mathrm{kB}$ activating signaling cascades $[16,18,31]$. Recently, numerous studies showed that A20 is inactivated by deletions and/or mutations in several lymphoma subtypes, including T-cell lymphomas [16-22], and A20 inhibition results in constitutive NF- $\kappa B$ activation in tumor cells. These data indicate that A20 inactivation might play a role in malignant T-cells. Bi- and monoallelic A20 deletions in a high proportion of Sezary syndrome patients were identified [16]; however, mutations and polymorphisms in A20 rarely occur in T-ALL [24]. Thus, it is of interest to characterize the $A 20$ expression pattern in T-ALLs containing an $A 20$ deletion. In this study, we examined the $A 20$ expression level and found significantly lower $A 20$ expression in T-ALL patients (median: 4.853) compared with healthy individuals (median: 8.748; $P=0.017$ ) (Figure 1A). Thus, we hypothesized that $A 20$ downregulation may be due to abnormal upstream regulation.

Antigen receptor-mediated NF- $\mathrm{kB}$ activation in lymphocytes relies on the formation of a large multi-protein complex containing CARMA1, BCL10, and MALT1 (CBM). MALT1 has proteolytic activity and controls T-cell activation by regulating NF- $\mathrm{kB}$ pathways [14,31], and it mediates rapid proteolytic cleavage and A20 inactivation [23]. Studies in MALT1-deficient mice have demonstrated an essential role for MALT1 in TCR- and B-cell receptor-mediated functions [15,28]. The CARMA1BCL10-MALT1 pathway is pathologically altered in several lymphoma subtypes [32], including activated B-cell-like diffuse large B-cell lymphoma (ABC-DLBCL) [33]. The CARMA1-BCL10-MALT1 pathway also plays a central role in TCR signaling that results in T-cell activation and proliferation [24,26-28,34]. In this study, we attempted to characterized alterations in the CBM genes in T-ALL. We examined the expression levels of the CARMA1, BCL10, and MALT1 genes, and significantly increased expression levels of CARMA1 (median: 2.916; $P=0.034$ ), $B C L 10$ (median: 0.285; $P=0.033$ ), and MALT1 (median: 1.201; $P=0.010$ ) were found in T-ALL patients compared with healthy individuals (median: $1.379,0.169$, and 0.677 , respectively) (Figure 1B-D). High expression of the CBM genes indicates significantly high leukemic T-cell activation, and high MALT1 expression might mediate A20 downregulation, which was found in the same T-ALL samples. This finding may also partially explain the lower expression level of A20 in T-ALL. Because CBM mediates TCR-induced NF- $\kappa B$ during T-cell activation, we further analyzed the expression level of $N F-\kappa B$, and as expected, $N F-\kappa B$ overexpression (median: 0.714 ) was found in T-ALL patients compared with healthy controls (median: $0.335 ; P=0.001$ ) (Figure $1 \mathrm{E}$ ). Overall, we show that the abnormal expression of CBM and $A 20$ in T-ALL cells may be related to the abnormal proliferation of malignant T-cells. This result is consistent with the finding that A20 is also a putative tumor suppressor in T-cell malignancies such as Sézary syndrome. In contrast, such abnormal expression characteristics may be considered as biomarkers or target factors in T-ALL.

Overexpression of CARMA1 was reported in angioimmunoblastic T-cell lymphoma and peripheral T-cell lymphoma, and it was linked to poor prognosis in a report by Fujiwara et al. [35]. Additionally, in a genome profile analysis of aggressive adult T-cell leukemia/lymphoma, CARMA1 was found to be a potential 7p22 amplification target gene in the lymphoma but not acute subtype. This finding suggests that the acute and lymphoma subtypes are genomically distinct; thus, they may develop tumors via distinct genetic pathways [7]. However, there are few reports of CBM molecular aberrations or dysfunction in T-ALL [4]. In this study, we found that all of the CBM genes were upregulated, resulting in the downregulation of $A 20$ and upregulation of $N F-\kappa B$, which may be a common characteristic of abnormal proliferation and activation in T-cell malignancies. Therefore, it is suggested that such overexpressed genes may be considered potentially attractive targets for the development of T-ALL therapeutics. It is well known that NF- $\mathrm{kB}$ is a target for multiple myeloma therapy via proteasome inhibitors such as 

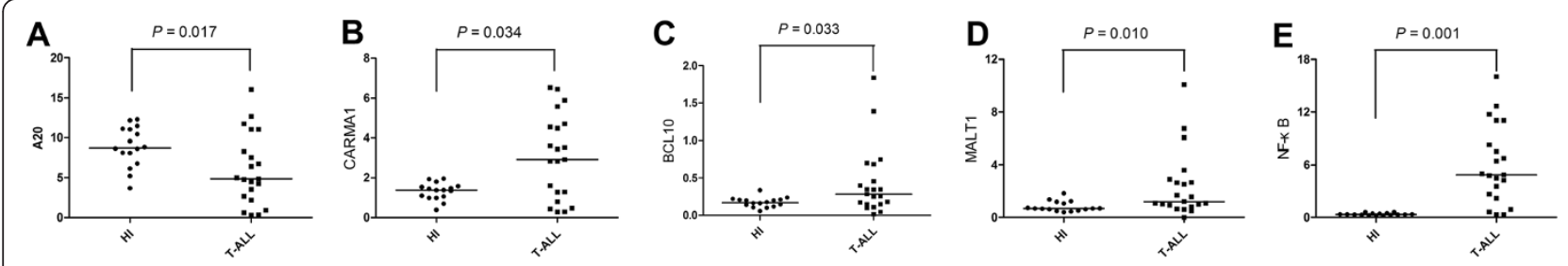

Figure 1 The expression levels of the (A) A20, (B) CARMA1, (C) BCL10, (D) MALT1, and (E) NF-KB genes in healthy individuals and patients with T-ALL.

bortezomib [36], which was also recently used in combined therapy for T-cell malignancies [37,38]. Moreover, two kinds of small molecule inhibitor for MALT1 have been reported recently. One of them is the phenothiazine derivative mepazine, which has been shown to have promising anticancer properties in subtypes of B-cell lymphoma and could also be used in the treatment of lymphocytemediated autoimmune pathologies such as multiple sclerosis [39]. The other one is MI-2 which binds directly to MALT1 and irreversibly suppresses protease function, and displays selective activity against ABC-DLBCL cell lines in vitro and xenotransplanted $\mathrm{ABC}-\mathrm{DLBCL}$ tumors in vivo. It would be worthy to investigate the anti-T-ALL effect of such Malt1 inhibitors [40].

We further analyzed associations between the expression patterns of the CBM, $A 20$, and $N F-\kappa B$ genes. A20 is generally cleaved by MALT1; thus, the expression level of MALT1 should be negatively correlated with the A20 and MALT1 expression pattern [41]. We found a negative correlation between the MALT1 and A20 expression levels ( $\mathrm{rs}=-0.806, P=<0.0001)$ in the healthy individual (Figure $2 \mathrm{~A}$ ) and T-ALL patient groups $(\mathrm{rs}=-0.450, P=$ 0.041 ; Figure $2 \mathrm{~B}$ ) as expected. A negative correlation was found between the $A 20$ and $N F-\kappa B$ expression levels (rs $=-0.847, P<0.0001$; Figure $2 \mathrm{C}$ ) in healthy individuals, as expected, while there was no significant correlation between the A20 and NF- $\mathrm{kB}$ expression levels in T-ALL patients ( $r s=0.0208, P=0.929$; Figure 2D). Moreover, the negative correlation was lost, and whether this is due to abnormal CMB regulation remains an open question. A positive correlation between the MALT1 and $N F-\kappa B$ expression level was also found in healthy controls ( $\mathrm{rs}=0.641, P=0.001$; Figure $2 \mathrm{E}$ ), while there was no significance in the correlation between genes in the T-ALL group ( $\mathrm{rs}=0.193, P=0.402$; Figure 2F). Moreover, we found a significant positive correlation between the gene expression levels of CARMA1 and BCL10 in healthy individuals ( $\mathrm{rs}=0.513, P=0.042$; Figure $2 \mathrm{G}$ ) and T-ALL patients ( $\mathrm{rs}=0.572, P=0.007$; Figure $2 \mathrm{H}$ ). Overall, this result indicates that MALT1, $A 20$, and $N F-\kappa B$ lose their normal expression pattern at the molecular level, and their manner of regulation in T-ALL may be more complex. In our previous studies, we found two T-ALL patients with two malignant $\mathrm{V} \delta 1$ and $\mathrm{V} \delta 2 \mathrm{~T}$-cell clones who had poor outcome, and high expression of the Notch1 and CARMA-BCL10-MALT1-A20-NF-KB pathway genes in this biclonal T-ALL patient group compared with a mono-malignant $\mathrm{V} \alpha \mathrm{T}$-cell clone was found [4]. Based

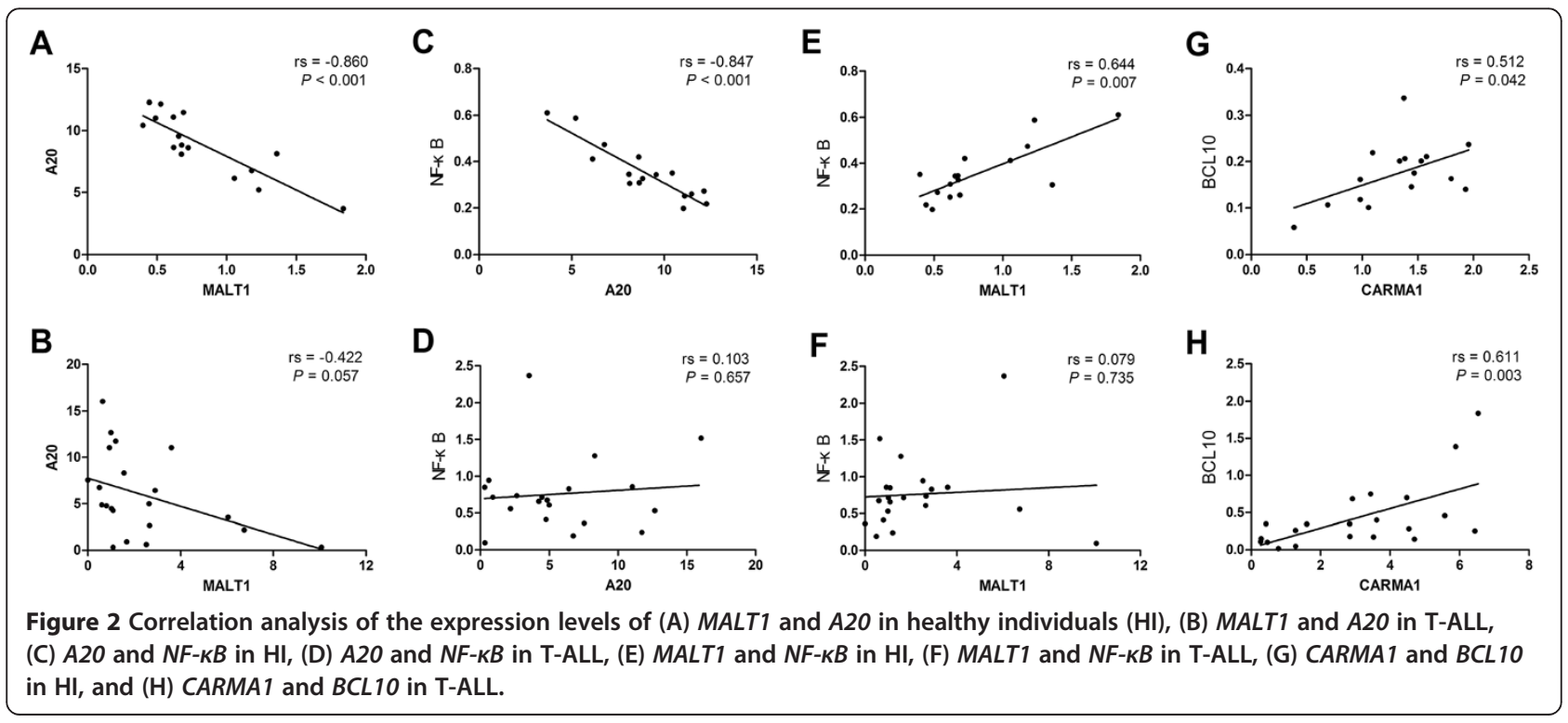


on our data, it is worth further investigating whether the different expression patterns of the CARMA-BCL10$M A L T 1-A 20-N F-\kappa B$ pathway genes may be a biomarker for a genomically-distinct subtype of T-ALL or a prognostic biomarker for T-ALL. Increasing new genetic markers for ALL have been found to have prognostic impact [42].

\section{Conclusions}

We first characterized the expression pattern of the CARMA-BCL10-MALT1-A20-NF-KB pathway genes and found that overexpression of CBM genes in T-ALL may cause constitutive cleavage and inactivation of A20 to enhance NF- $\mathrm{kB}$ signaling, contributing to the pathogenesis of T-ALL. Thus, this pathway may be considered a potentially attractive target for the development of $\mathrm{T}$ ALL therapeutics. However, this finding is based only on results from a limited case analysis and further research involving more samples is needed to determine representative results. Moreover, the change of protein levels of this pathway are needed to confirm this, especially for target therapeutic strategy in T-ALL.

\begin{abstract}
Abbreviations
ABC-DLBCL: Activated B-cell-like diffuse large B-cell lymphoma; A20: Tumor necrosis factor alpha-induced protein 3 (TNFAIP3); BCl-10: B-cell lymphoma 10; BCL11B: B-cell chronic lymphocytic leukemia/lymphoma11B); $\beta 2 \mathrm{M}$ : B2-microglobulin; CARMA1: Caspase-recruitment domain (CARD) containing membrane-associated guanylate kinase protein 1 (CARD11); CBM: CARMA1, BCL10, and MALT1; MALT1: Mucosa-associated-lymphoid-tissue lymphomatranslocation gene 1; NF-kB: Nuclear factor KB; PBMCs: Peripheral blood mononuclear cells; qRT-PCR: Quantitative real-time RT-PCR; T-ALL: T-cell acute lymphoblastic leukemia; TCR: T-cell receptor.
\end{abstract}

\section{Competing interests}

The authors declare that they have no competing interests.

\section{Authors' contributions}

YQL and XLW contributed to the concept development and study design YM, LHZ, YX, ZYZ, XW, and FZ performed the real-time PCR. SHC and LY performed PBMC isolation, RNA extraction, and CDNA synthesis. GXL and XH were responsible for the collection of clinical data. YQL, XLW, SUH, YM, and $\mathrm{LHZ}$ coordinated the study and helped draft the manuscript. All authors read and approved the final manuscript.

\section{Acknowledgments}

This study was supported by grants from the National Natural Science Foundation of China (Nos. 91129720, 81100384), the Guangdong Science \& Technology Project (2012B050600023), Science and Technology Innovation Key Project of Guangdong Higher Education Institutes (kjcxzd1013), the Medical Science Foundation of Guangdong Province (A2014371), and the Guangdong provincial undergraduate training program for innovation and entrepreneurship (1055912064).

\section{Author details}

${ }^{1}$ Institute of Hematology, Jinan University, Guangzhou 510632, China. ²Department of Medicine, Imperial College London, St Mary's Campus, London W2 1PG, UK. ${ }^{3}$ Key Laboratory for Regenerative Medicine of Ministry of Education, Jinan University, Guangzhou 510632, China. ${ }^{4}$ Department of Hematology, Guangdong General Hospital (Guangdong Academy of Medical Sciences), Guangzhou 510080, People's Republic of China. ${ }^{5}$ Department of Biochemistry and Molecular Biology, College of Medicine, University of Florida, Gainesville, FL 32610-3633, USA.
Received: 4 September 2014 Accepted: 28 October 2014

Published online: 11 November 2014

\section{References}

1. Aifantis I, Raetz E, Buonamici S: Molecular pathogenesis of T-cell leukaemia and lymphoma. Nat Rev Immunol 2008, 8:380-390.

2. Morris JC, Waldmann TA, Janik JE: Receptor-directed therapy of T-cell leukemias and lymphomas. J Immunotoxicol 2008, 5:235-248.

3. Pui CH, Relling MV, Downing JR: Acute lymphoblastic leukemia. N Engl J Med 2004, 350:1535-1548.

4. Zheng H, Wang X, Ma Y, Xu B, Chen S, Yang L, Wu X, Przybylski GK, Huang $S, Y e T, L i Y$ : The TCR gammadelta repertoire and relative gene expression characteristics of T-ALL cases with biclonal malignant Vdelta1 and Vdelta2 T cells. DNA Cell Biol 2014, 33:49-56.

5. Gimenes-Teixeira HL, Lucena-Araujo AR, Dos Santos GA, Zanette DL, Scheucher PS, Oliveira LC, Dalmazzo LF, Silva-Junior WA, Falcao RP, Rego EM: Increased expression of miR-221 is associated with shorter overall survival in T-cell acute lymphoid leukemia. Exp Hematol Oncol 2013, 2:10.

6. Chen S, Huang X, Zheng H, Geng S, Wu X, Yang L, Weng J, Du X, Li Y: The evolution of malignant and reactive $\gamma \delta+T$ cell clones in a relapse T-ALL case after allogeneic stem cell transplantation. Mol Cancer 2013, 12:73.

7. Oshiro A, Tagawa H, Ohshima K, Karube K, Uike N, Tashiro Y, Utsunomiya A, Masuda M, Takasu N, Nakamura S, Morishima Y, Seto M: Identification of subtype-specific genomic alterations in aggressive adult T-cell leukemia/ lymphoma. Blood 2006, 107:4500-4507.

8. Vanura K, Vrsalovic MM, Le T, Marculescu R, Kusec R, Jager U, Nadel B: V(D)J targeting mistakes occur at low frequency in acute lymphoblastic leukemia. Genes Chromosomes Cancer 2009, 48:725-736.

9. Lin C, Zheng H, Wang C, Yang L, Chen S, Li B, Zhou Y, Tan H, Li Y: Mutations increased overexpression of Notch1 in T-cell acute lymphoblastic leukemia. Cancer Cell Int 2012, 12:13.

10. Zou J, Li P, Lu F, Liu N, Dai J, Ye J, Qu X, Sun X, Ma D, Park J, Ji C: Notch 1 is required for hypoxia-induced proliferation, invasion and chemoresistance of T-cell acute lymphoblastic leukemia cells. J Hematol Oncol 2013, 6:3.

11. Liu N, Zhang J, Ji C: The emerging roles of Notch signaling in leukemia and stem cells. Biomark Res 2013, 1:23.

12. Patel B, Kang Y, Cui K, Litt M, Riberio MS, Deng C, Salz T, Casada S, Fu X, Qiu Y, Zhao K, Huang S: Aberrant TAL1 activation is mediated by an interchromosomal interaction in human T-cell acute lymphoblastic leukemia. Leukemia 2014, 28:349-361.

13. Huang $X, D u$ X, Li Y: The role of BCL11B in hematological malignancy. Exp Hematol Oncol 2012, 1:22.

14. Chen Y, Liu S, Shen Q, Zha X, Zheng H, Yang L, Chen S, Wu X, Li B, Li Y: Differential gene expression profiles of PPP2R5C-siRNA-treated malignant T cells. DNA Cell Biol 2013, 32:573-581.

15. Thome M: Multifunctional roles for MALT1 in T-cell activation. Nat Rev Immunol 2008, 8:495-500.

16. Zhang F, Yang L, Li Y: The role of $A 20$ in the pathogenesis of lymphocytic malignancy. Cancer Cell Int 2012, 12:44.

17. Braun FC, Grabarczyk P, Mobs M, Braun FK, Eberle J, Beyer M, Sterry W, Busse F, Schroder J, Delin M, Przybylski GK, Schmidt CA: Tumor suppressor TNFAIP3 (A20) is frequently deleted in Sezary syndrome. Leukemia 2011, 25:1494-1501

18. Chanudet E, Huang Y, Zeng N, Streubel B, Chott A, Raderer M, Du MQ: TNFAIP3 abnormalities in MALT Iymphoma with autoimmunity. $\mathrm{Br} J$ Haematol 2011, 154:535-539.

19. Kato M, Sanada M, Kato I, Sato Y, Takita J, Takeuchi K, Niwa A, Chen Y, Nakazaki K, Nomoto J, Asakura Y, Muto S, Tamura A, lio M, Akatsuka Y, Hayashi Y, Mori H, Igarashi T, Kurokawa M, Chiba S, Mori S, Ishikawa Y, Okamoto K, Tobinai K, Nakagama H, Nakahata T, Yoshino T, Kobayashi Y, Ogawa S: Frequent inactivation of A20 in B-cell lymphomas. Nature 2009, 459:712-716.

20. Compagno M, Lim WK, Grunn A, Nandula SV, Brahmachary M, Shen Q Bertoni F, Ponzoni M, Scandurra M, Califano A, Bhagat G, Chadburn A, Dalla-Favera R, Pasqualucci L: Mutations of multiple genes cause deregulation of NF-kappaB in diffuse large B-cell lymphoma. Nature 2009, 459:717-721.

21. Honma K, Tsuzuki S, Nakagawa M, Tagawa H, Nakamura S, Morishima Y, Seto M: TNFAIP3/A20 functions as a novel tumor suppressor gene in several subtypes of non-Hodgkin lymphomas. Blood 2009, 114:2467-2475. 
22. Novak U, Rinaldi A, Kwee I, Nandula SV, Rancoita PM, Compagno M, Cerri M, Rossi D, Murty W, Zucca E, Gaidano G, Dalla-Favera R, Pasqualucci L, Bhagat $G$, Bertoni F: The NF-\{kappa\}B negative regulator TNFAIP3 (A20) is inactivated by somatic mutations and genomic deletions in marginal zone lymphomas. Blood 2009, 113:4918-4921.

23. Schmitz R, Hansmann ML, Bohle V, Martin-Subero Jl, Hartmann S, Mechtersheimer G, Klapper W, Vater I, Giefing M, Gesk S, Stanelle J, Siebert R, Kuppers R: TNFAIP3 (A20) is a tumor suppressor gene in Hodgkin lymphoma and primary mediastinal B cell lymphoma. J Exp Med 2009, 206:981-989.

24. Coornaert B, Baens M, Heyninck K, Bekaert T, Haegman M, Staal J, Sun L, Chen ZJ, Marynen P, Beyaert R: T cell antigen receptor stimulation induces MALT1 paracaspase-mediated cleavage of the NF-kappaB inhibitor A20. Nat Immunol 2008, 9:263-271.

25. Zhu L, Zhang F, Shen Q, Chen S, Wang X, Wang L, Yang L, Wu X, Huang S, Schmidt CA, Li Y: Characteristics of A20 gene polymorphisms in T-cell acute lymphocytic leukemia. Hematology 2014, Epub ahead of print.

26. Ruland J, Duncan GS, Wakeham A, Mak TW: Differential requirement for Malt1 in T and B cell antigen receptor signaling. Immunity 2003, 19:749-758

27. Li S, Yang X, Shao J, Shen Y: Structural insights into the assembly of CARMA1 and BCL10. PLoS One 2012, 7:e42775.

28. Hara H, lizasa E, Nakaya M, Yoshida H: L-CBM signaling in lymphocyte development and function. J Blood Med 2010, 1:93-104.

29. Wang $X, X u$, , Liang L, Xu Y, Wang C, Wang L, Chen S, Yang L, Wu X, Li B, Luo G, Tan H, Li W, Li Y: Abnormal expression of A20 and its regulated genes in peripheral blood from patients with lymphomas. Cancer Cell Int 2014, 14:36.

30. Shi L, Chen S, Lu Y, Wang X, Xu L, Zhang F, Yang L, Wu X, Li B, Li Y: Changes in the MALT1-A20-NF-kappaB expression pattern may be related to T cell dysfunction in AML. Cancer Cell Int 2013, 13:37.

31. Vereecke $L$, Beyaert $R$, van Loo G: The ubiquitin-editing enzyme $A 20$ (TNFAIP3) is a central regulator of immunopathology. Trends Immunol 2009, 30:383-391.

32. Fontan L, Melnick A: Molecular pathways: targeting MALT1 paracaspase activity in lymphoma. Clin Cancer Res 2013, 19:6662-6668.

33. Bidere N, Ngo VN, Lee J, Collins C, Zheng L, Wan F, Davis RE, Lenz G, Anderson DE, Arnoult D, Vazquez A, Sakai K, Zhang J, Meng Z, Veenstra TD, Staudt LM, Lenardo MJ: Casein kinase 1alpha governs antigen-receptorinduced NF-kappaB activation and human lymphoma cell survival. Nature 2009, 458:92-96.

34. Lin X, Wang D: The roles of CARMA1, Bcl10, and MALT1 in antigen receptor signaling. Semin Immunol 2004, 16:429-435.

35. Fujiwara SI, Yamashita Y, Nakamura N, Choi YL, Ueno T, Watanabe $H$, Kurashina K, Soda M, Enomoto M, Hatanaka H, Takada S, Abe M, Ozawa K, Mano $\mathrm{H}$ : High-resolution analysis of chromosome copy number alterations in angioimmunoblastic T-cell lymphoma and peripheral T-cell lymphoma, unspecified, with single nucleotide polymorphism-typing microarrays. Leukemia 2008, 22:1891-1898.

36. Kouroukis TC, Baldassarre FG, Haynes AE, Imrie K, Reece DE, Cheung MC: Bortezomib in multiple myeloma: systematic review and clinical considerations. Curr Oncol 2014, 21:e573-e603.

37. Chaoui D, Bouallegue S, Arakelyan N, Genet P, Aljijakli A, Sutton L: Bortezomib, lenalidomide and dexamethasone (VRD) combination as salvage therapy in refractory angioimmunoblastic $T$ cell lymphoma. Br J Haematol 2014, 164:750-752.

38. Yu P, Petrus MN, Ju W, Zhang M, Conlon KC, Nakagawa M, Maeda M, Bamford RN, Waldmann TA: Augmented efficacy with the combination of blockade of the NOTCH-1 pathway, Bortezomib and Romidepsin in a murine MT-1 adult T cell leukemia model. Leukemia 2014, Epub ahead of print.

39. Mc Guire C, Elton L, Wieghofer P, Staal J, Voet S, Demeyer A, Nagel D, Krappmann D, Prinz M, Beyaert R, van Loo G: Pharmacological inhibition of MALT1 protease activity protects mice in a mouse model of multiple sclerosis. J Neuroinflammation 2014, 11:124.

40. Fontan L, Yang C, Kabaleeswaran V, Volpon L, Osborne MJ, Beltran E, Garcia M, Cerchietti L, Shaknovich R, Yang SN, Fang F, Gascoyne RD, MartinezCliment JA, Glickman JF, Borden K, Wu H, Melnick A: MALT1 small molecule inhibitors specifically suppress $A B C-D L B C L$ in vitro and in vivo. Cancer Cell 2012, 22:812-824

41. Malinverni C, Unterreiner A, Staal J, Demeyer A, Galaup M, Luyten M, Beyaert R, Bornancin F: Cleavage by MALT1 induces cytosolic release of A20. Biochem Biophys Res Commun 2010, 400:543-547.

42. Zhao $Y$, Huang $H$, Wei G: Novel agents and biomarkers for acute lymphoid leukemia. J Hematol Oncol 2013, 6:40.

doi:10.1186/s40001-014-0062-8

Cite this article as: Ma et al:: Characteristics of CARMA1-BCL10-MALT1

$A 20-N F-K B$ expression in T cell-acute lymphocytic leukemia. European Journal of Medical Research 2014 19:62.

\section{Submit your next manuscript to BioMed Central and take full advantage of:}

- Convenient online submission

- Thorough peer review

- No space constraints or color figure charges

- Immediate publication on acceptance

- Inclusion in PubMed, CAS, Scopus and Google Scholar

- Research which is freely available for redistribution

Submit your manuscript at www.biomedcentral.com/submit
C) Biomed Central 